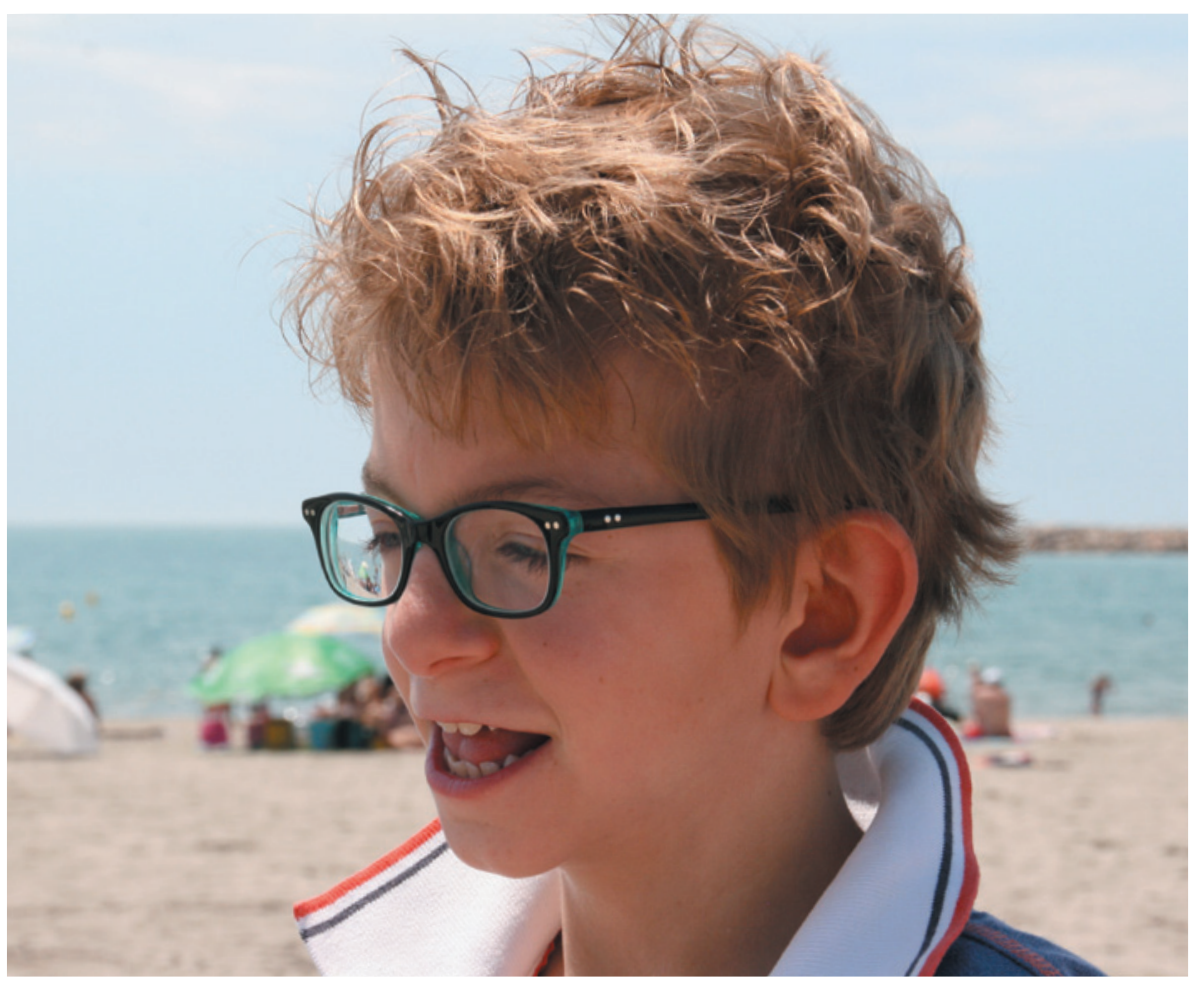

Exome sequencing could help to identify the causes of intellectual disability in children such as Siebe.

MEDICAL GENETICS

\title{
Gene hunt is on for mental disability
}

\section{Pioneering clinical genome-sequencing projects focus on patients with developmental delay.}

\section{BY EWEN CALLAWAY}

$\mathrm{M}$ edical geneticists are giving genome sequencing its first big test in the clinic by applying it to some of their most baffling cases. By the end of this year, hundreds of children with unexplained forms of intellectual disability and developmental delay will have had their genomes decoded as part of the first large-scale, national clinical sequencing projects.

These programmes, which were discussed last month at a rare-diseases conference held at the Wellcome Trust Genome Campus in Hinxton, UK, aim to provide a genetic diagnosis that could end years of uncertainty about a child's disability. In the longer term, they could provide crucial data that will underpin efforts to develop therapies. The projects are also highlighting the logistical and ethical challenges of bringing genome sequencing to the consulting room. "The overarching theme is that genome-based diagnosis is now hitting mainstream medicine," says Han Brunner, a medical geneticist at the Radboud University Nijmegen Medical Centre in the Netherlands, who leads one of the projects.

About $2 \%$ of children experience some form of intellectual disability. Many have disorders such as Down's syndrome and fragile $\mathrm{X}$ syndrome, which are linked to known genetic abnormalities and so are easily diagnosed. Others have experienced environmental risk factors, such as fetal alcohol exposure, that rule out a simple genetic explanation. However, a large proportion of intellectual disability cases are thought to be the work of single, as-yetunidentified mutations.

Scientists estimate that about 1,000 genes are involved in the function of the healthy brain. "There are so many genes that can go wrong and give you intellectual disability," says André Reis, a medical geneticist at Erlangen University Hospital in Germany. Reis's group, the German Mental Retardation Network, has already sequenced the exomes - the 1-2\% of the genome that contains instructions for building proteins - of about 50 patients with severe intellectual disability.

Joining the hunt is a UK-based programme called Deciphering Developmental Disorders, which expects to sequence 1,000 exomes by the year's end, with an ultimate goal of diagnosing up to 12,000 British children with developmental delay. A Canadian project called FORGE (finding of rare disease genes) aims to sequence children and families with 200 different disorders this year. And in the United States, the National Human Genome Research Institute in Bethesda, Maryland, recently funded three Mendelian Disorders Sequencing Centers that will apply genome sequencing to diagnosing thousands of patients with a wider range of rare diseases, including intellectual disability and developmental delay.

\section{FIRST GLANCE}

Early results are coming in from Brunner's team, which has already sequenced about 100 exomes of children with intellectual disability. By comparing the children's exomes with those of the parents, the researchers have identified new mutations - potential causes of the disorder - in as many as $40 \%$ of the cases. The other programmes are having similar success at making possible genetic diagnoses.

In most cases, identifying mutations will not point to medical treatments, let alone cures. But scientists say the importance of a diagnosis should not be discounted. "Parents have been struggling with the delay of their children for years. They have gone from one doctor to the next, had all kinds of tests done on their children looking for an explanation," Reis says. Knowing that the mutation causing a child's intellectual disability is new rather than inherited can also reassure parents that other children they conceive are unlikely to have the same disease.

Treatments could eventually follow. The projects are guiding research in mice, zebrafish and fruitflies, with the goal of unpicking the mechanisms of mental disorders. But it will undoubtedly be a long time before any potential therapies are tried in humans: an early-stage clinical trial of a drug to treat fragile $\mathrm{X}$ syndrome, for example, was published last year (S. Jacquemont et al. Sci. Transl. Med. 3, 64ra1; 2011), some two decades after the gene underlying the condition, $F M R 1$, was identified.

The work is also throwing up a fresh challenge: how can scientists be sure that a specific mutation is the cause of a particular form of
DNATURE.COM Read more about 'genomes on prescription' at: go.nature.com/yv7rls mental disability? "It's not clear what is the threshold of evidence at which you can say this is the causal variant in this patient," says 
Daniel MacArthur, a geneticist at Massachusetts General Hospital in Boston. In a recent Science paper, his team estimated that the average healthy genome contains about 100 genedisabling mutations. Such 'background noise' could lead scientists astray in their hunt for causal mutations.

Brunner says that about half of the mutations his team has identified have previously been seen in other patients with similar forms of intellectual disability, offering enough assurance to make a diagnosis. Circumstantial evidence, such as indications that the mutation disrupts a gene expressed in the brains of animals, ties the other half of the mutations to intellectual disability. But making a solid case often requires identifying second, third and fourth patients with similar mutations and symptoms.

Scientists are already forging these connections on an informal basis. At the Wellcome Trust meeting, several groups reported mutations in a gene called ARID1B in patients with intellectual disability. James Lupski, a medical geneticist at Baylor College of Medicine in Houston, Texas, says that when his team identifies a potentially disease-causing mutation in a patient genome, he e-mails other scientists to see whether they have found similar mutations.

But researchers agree that they need a more

formalized way to make these connections. To that end, the US National Center for Biotechnology Information in Bethesda is developing a database, ClinVar, to integrate clinical and genetic data; others, such as DECIPHER, run by the Sanger Institute, handle genetic data such as chromosome rearrangements that can disrupt genes.

The first clinical sequencing projects are also grappling with what they should or shouldn't tell patients. "We don't want people coming into our clinic for intellectual disability and

\section{"Genome- \\ based diagnosis is now hitting mainstream medicine."} coming out with a cancer gene; this is not what they came for," says Reis.

Brunner's team once had to face just that situation. The researchers identi-

fied a mutation in a gene in one patient that could increase the risk of colon cancer as an adult. The project's ethical review board had determined that if families wanted to know of mutations potentially underlying a child's intellectual disability, they must also be willing to receive such incidental findings, and so the child's parents were told. But clinical sequencing projects vary in their approach to incidental results. For the time being, Deciphering Developmental Disorders will not inform families about such findings. For FORGE Canada, the policy varies from province to province.

A working group convened by the American College of Medical Genetics and Genomics in Bethesda recently suggested drawing up a list of gene mutations that ought to be routinely reported back to patients. The list would include mutations strongly linked to conditions for which a medical intervention is available.

"This is a fast-changing ethical environment," says Matt Hurles, a geneticist at the Sanger Institute and one of the leaders of Deciphering Developmental Disorders. His team is conducting a web-based survey to gauge the attitudes of parents, physicians and the general public towards disclosing incidental genomic findings. Lupski admits, "We're learning as we go along. People don't want to hear that, but that's the truth of the matter."

Scientists and clinicians hope that the lessons learned in these initial large-scale clinical sequencing projects will inform genomic medicine as it reaches more patients and moves to other specialities, such as neurology and cardiology, and even to routine health care. "If in five years time this project hasn't catalysed the adoption of genomic technologies which have been shown to be useful, in some degree we will have failed," says Hurles. 